\title{
Behavioural studies on the peppered moth Biston betularia and a discussion of the role of pollution and lichens in industrial melanism
}

\author{
TONY G. LIEBERT
}

The Heathfield, Crowcombe Heathfield, Lydeard St Lawrence, Taunton

AND

PAUL M. BRAKEFIELD*

Department of Zoology, University College, P.O. Box 78, Cardiff CF1 1XL

Received 21 November 1986, accepted for publication 2 February 1987

We examined the resting behaviour during pairing and egg-laying of bred female Biston betularia (L.) after they were set free at wooded sites in Somerset and Cardiff. Moths were not released immediately on emergence but were held for three nights to overcome an initial period of flight activity. Females $(\mathcal{N}=257)$ were placed on trunks, and on large and small branches of trees, especially oaks, over periods of several weeks in 1984, 1985 and 1986 . Releases were not made within $50 \mathrm{~m}$ of any known survivor. One hundred and thirty-one pairings were observed. We also examined oviposition behaviour in a cage experiment using different types of branches.

Our observations support Mikkola's earlier conclusion from cage experiments with male moths that the species rests predominantly on branches and shows an appropriately specialized resting attitude, demonstrated here in a series of photographs. Many moths will rest underneath, or on the side of, narrow branches in the canopy. Once released females had settled and paired they only moved quite short distances, but positioning and egg-laying were profoundly influenced by the presence of foliose lichens. Females of all phenotypes show a strong preference to oviposit beneath a thallus of foliose lichens. Their tendency to rest against or close to the lichen during the day could markedly influence their crypsis. In the absence of foliose lichens, eggs are laid in cracks in the bark.

The survivorship of released females both in different pairing combinations and during their whole reproductive life-span is analysed. These preliminary data suggest that bird predation can give rise to differential mortality of different pairing combinations and of the phenotypes. This technique provides a powerful method of measuring the relative crypsis and differential mortality of phenotypes with living females in natural resting sites.

The significance of our observations on resting behaviour is discussed with regard to the role of air pollution and epiphytes in industrial melanism. Particular attention is given to the causal mechanisms underlying recent declines in the frequency of carbonaria melanics in parts of Britain. One important factor is the new growth made by trees since the marked reduction in particulate air pollution in the 1960s. It is emphasized that we need to know much more about the interactions between pollution, epiphytes and resting backgrounds, especially in the canopy, before we can be confident of our understanding of the evolution of industrial melanism.

KEY WORDS: Biston betularia - melanism - resting behaviour - pairings - branches - epiphytes foliose lichens - oviposition - crypsis - predation.

* To whom reprint requests should be sent. 


\section{CONTENTS}

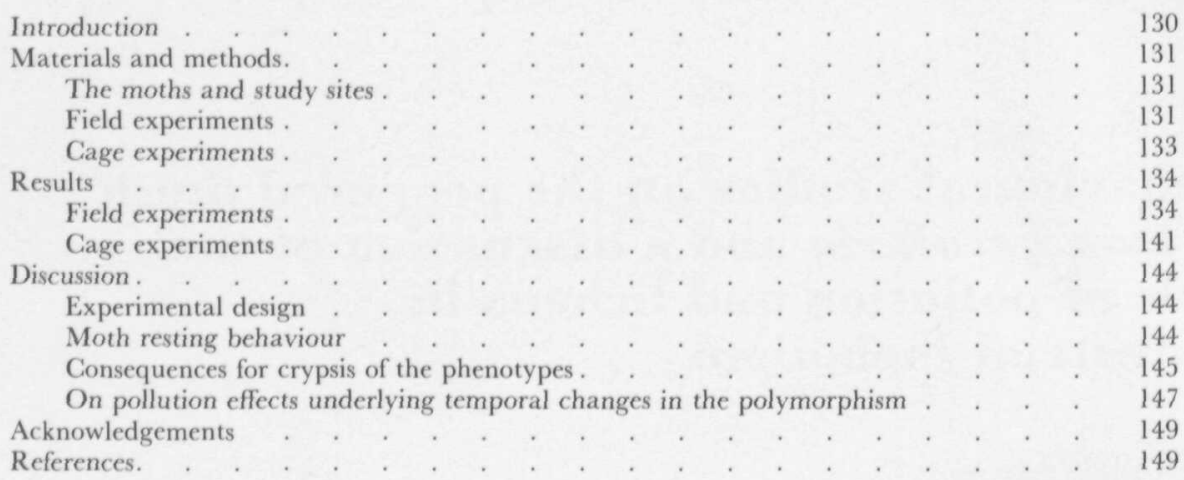

\section{INTRODUCTION}

The classic textbook example of the evolution of an adaptation to a novel environment and of the spread of adaptive phenotypes by natural selection remains that of industrial melanism in the peppered moth Biston betularia (L.) (reviews by Kettlewell, 1973; Lees, 1981). Particularly compelling evidence for some features of the phenomenon, and especially its general basis in air pollution, comes from recent evidence for some dramatic local and more general declines in melanic frequency correlated with lower amounts of pollutants during the implementation of the clean air legislation in Britain over the past 20 or so years (Clarke, Mani \& Wynne, 1985; Cook, Mani \& Varley, 1986). Yet several workers have emphasized the inadequacies in our understanding of the dynamics of the process and the mechanisms involved in maintenance of the polymorphism in the extreme environments of industrial centres in western Europe, especially northern England (e.g. Mikkola, 1984; Brakefield, 1987). This paper describes observations on the behaviour of $B$. betularia critical to resolving some of these inadequacies.

The experimental work of the last 30 years has concentrated on (1) surveying geographical variation in the frequency of melanics, (2) investigating the survivorship, and sometimes the dynamics, of whole cohorts of melanic and nonmelanic moths in different environments, and (3) performing crosses to examine the genetics of the polymorphism and segregation ratios. This 'population' and laboratory breeding approach has led to extensive survey data and some estimates of ecological parameters and visual selection.

Comparatively recent theoretical modelling studies incorporating the estimates of visual selection and migration have indicated that a balance between selective predation and gene flow is not sufficient to account fully for the polymorphism (Mani, 1980, 1982). The matching between predicted and observed patterns of spatial variability in allele frequencies is substantially improved by including non-visual differences in fitness between phenotypes. Some support for such differences, although not in the precise form suggested by the models, comes from analysis of deviations from expected segregation ratios in reared material (Creed, Lees \& Bulmer, 1980). However, our understanding of the parameters describing gene flow and of visual selection probably requires refining. In the case of the former, we have yet to take into account passive wind 
dispersal by larvae (Kettlewell, 1973). Mikkola (1979, 1984) gives an important critique of the predation experiments performed using dead moths glued to trees or releases of marked males. In particular, he describes cage experiments, with male moths, which strongly suggest that the normal resting sites are on upper branches, while the predation experiments have all been based on the survivorship of moths on tree trunks. Howlett \& Majerus (1987) also include records for small numbers of moths found in nature, which support Mikkola's findings.

We have noted the extreme differences which may occur within a tree from its base to the upper canopy in the colour, texture and epiphyte growth on its bark. We believe that the determination of the details of the resting behaviour of Biston moths in relation to such variability within, and also between, trees in different habitats is critical to improving our understanding of visual selection acting on the polymorphism. In this paper we are concerned with the relationships between epiphytes and adult moths as the central problem. We describe observations of the resting behaviour and survivorship of moths in natural conditions in a rural and a polluted environment, or in experimental cages. Unlike Mikkola $(1979,1984)$ we have worked principally with females. Our investigations cover the period of nearly $24 \mathrm{~h}$ during which moths remain in copula and the subsequent period when females lay their eggs. Kettlewell (1973) suggests that the period of pairing could be critical since the crypsis of unlike pairings is likely to differ from that of like pairings. Bishop \& Cook (1975) indicate the importance of the fecundity and survivorship curves of egg laying females. Figure 1 illustrates the possible consequences for the relative crypsis by comparing single and paired moths of varying phenotype on different resting backgrounds. Our results are discussed with regard to the opportunities for investigating the dynamics of present-day declines in melanic frequency.

\section{MATERIALS AND METHODS}

\section{The moths and study sites}

Non-melanic typica, melanic carbonaria and intermediate insularia moths were reared in sleeves using material from Merseyside, Weston-super-Mare and Taunton. Most field experiments were carried out from 20 April to 28 May 1984 and 20 May to 19 June 1985 in wooded countryside at Lydeard St Laurence near Taunton in rural Somerset. The local population of B. betularia has a low frequency of melanics (numbers of typica: insularia : carbonaria$1972=144: 18: 2 ; 1978=88: 7: 1)$. An additional experiment was performed from 7 June to 9 July 1986 in an area of semi-natural woodland within Roath Park, Cardiff in South Wales. Air pollution in this medium-sized city has brought about significant changes in epiphyte floras and bark coloration. Dark insularia is the dominant phenotype with about $40 \%$ typica and less than $10 \%$ carbonaria (Lees, 1981). In each area the woodland includes mature oak trees (Quercus spp.).

\section{Field experiments}

Mikkola (1984) describes the strong response of male moths after eclosion from the pupae at ground level to climb upwards on trees before flying. Our 

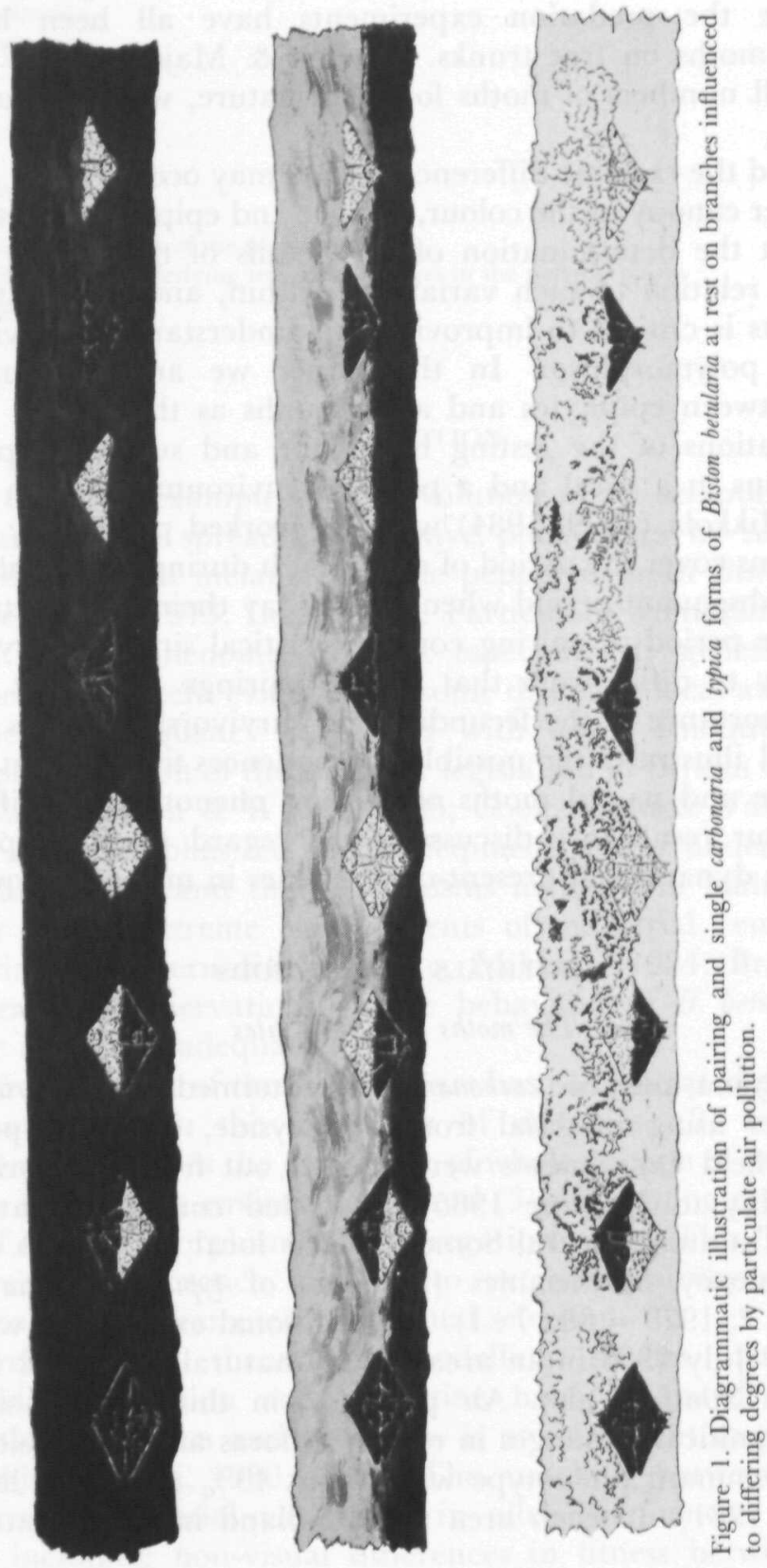
trials showed that female moths held for three or (sometimes) more nights after eclosion exhibited a progressively weaker tendency to fly and to climb. Our field experiments are based on releases of such moths on to trunks, main branches or outer branchlets of various species of tree, especially oak. Releases were made shortly before dusk. The precise positions of females remaining on the tree were then recorded following pairing after dark, early the next morning in daylight and on all subsequent mornings and evenings. The phenotype of copulating moths was recorded. New releases were only made when there was no known survivor within $50 \mathrm{~m}$, to minimize the numbers of moths within individual bird feeding territories. Less than ten, and usually about five moths were released on individual evenings. Most pairings were with local males although some released males also mated. The numbers of moths released in the Somerset experiments were 123 (1984) and 63 (1985), and at Cardiff, 71. The 1985 experiments were designed principally to examine the effects of branch form and size on resting behaviour. Moths of each phenotype were sometimes released on specific backgrounds. Therefore, the data on their survivorship are not analysed.

\section{Cage experiments}

Observations of the resting site selection of female moths and their oviposition behaviour were also made using a cage consisting of a $1 \mathrm{~m}$ long polythene tunnel (Fig. 2). The cage was located outdoors in shade below a large apple tree. It contained two of a set of three branches of similar dimensions (Fig. 2) but with different epiphyte covers. Branch 1 was from the canopy of a large rural oak. The foliose lichens, Hypogymnia physodes and Parmelia sulcata, and the fruticose species, Evernia prunastri and Usnea subfloridana, covered about one-third of the upper surface extending beyond the midline in places. Hypogymnia physodes was the dominant species on one end (A), and P. sulcata on the other (B). The lower surface was a pale, creamy green due to the alga Desmococcus viridis, and the
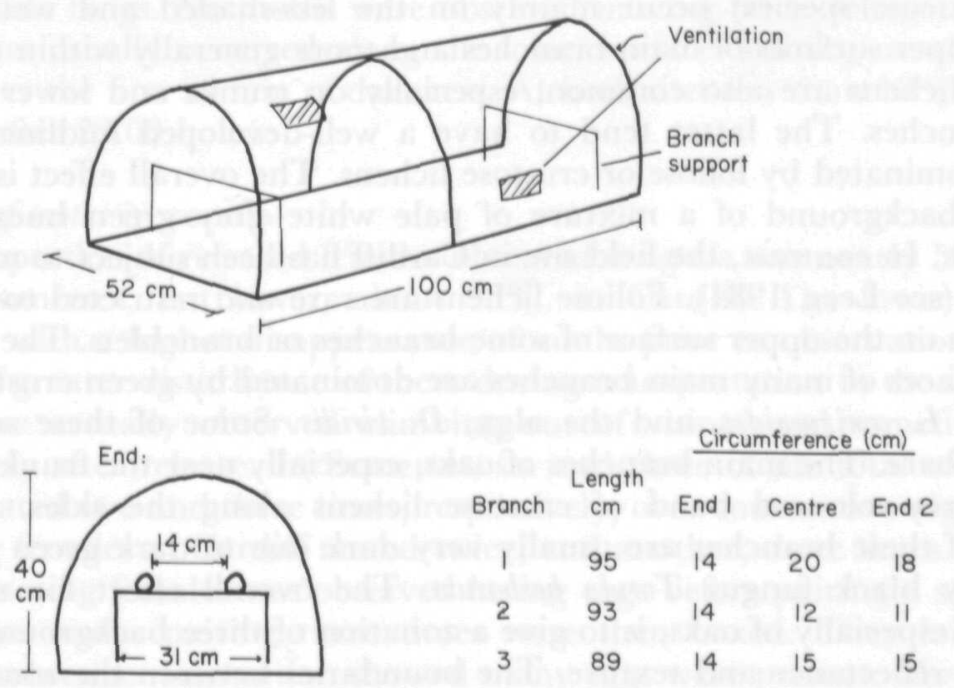

Figure 2. Side and end elevations of the experimental cage with details of the size of the branches. 
crustose lichens Lecanora conizaeoides and Lepraria incana. Branch 2 was from the canopy of an ash (Fraxinus excelsior). One half (A) had no lichens established on its upper surface but had two areas of cracks where side branches had been present. A similar foliose lichen cover as on branch 1A occurred on the other end of this branch (B). The lower surface of each end had a thin and partial covering of algae and crustose lichens. Branch 3 was from a dead oak: it was in good condition but all surfaces had numerous cracks, considerably more than are characteristic of living lichen-free branches; no lichens or algae were present. Cracks occurred on the end sections of each branch and where any side branches had been removed.

The cage experiment was performed from 1-26 June 1985. Branches and moths were changed each evening. Two branches and their relative positions and orientation were selected according to a predetermined random series. Pairings of Biston betularia were obtained each day in sleeves using newly emerged females. Following separation, three females were introduced between 20.30 and 21.00 hours on to different ends of the branches in a fixed sequence of f. insularia, f. carbonaria and f. typica. The total numbers of these phenotypes used were 25,25 and 23 , respectively. The released moths showed very little or no tendency to fly. Daily observations on branch and resting site choice, and on oviposition behaviour were made at 22.30 and 08.00 hours, and then at regular intervals up to 20.30 hours when the moths were removed and the experiment reset.

\section{RESULTS}

\section{Field experiments}

Epiphytic floras and resting surfaces at each site

Most trees in Somerset supported epiphyte floras typical of rural England (see, for examples, Bishop, Cook, Muggleton \& Seaward, 1975). Foliose lichens (with fruticose species) occur mainly on the less-shaded and wetter sides of trunks, upper surfaces of main branches and more generally within the canopy. Crustose lichens are also common, especially on trunks and lower surfaces of main branches. The latter tend to have a well-developed midline separating regions dominated by foliose or crustose lichens. The overall effect is of a rough textured background of a mixture of pale white-grey-green hues with high reflectance. In contrast, the field site in Cardiff has been subject to moderate air pollution (see Lees, 1981). Foliose lichens are rare and restricted to small spots or patches on the upper surface of some branches or branchlets. The trunks and lower surfaces of many main branches are dominated by green crustose lichens, especially $L$. conizaeoides, and the alga, D. viridis. Some of these surfaces are, however, bare. The main branches of oaks, especially near the trunk, frequently have a grey-coloured band of crustose lichens along the sides. The upper surfaces of these branches are usually very dark due to dark green mosses and the nearly black fungus Torula herbarum. The overall effect for many main branches, especially of oaks, is to give a zonation of three backgrounds differing in colour, reflectance and texture. The boundaries between the zones are often remarkably sharp. The smaller branchlets of the canopies of oaks are almost 
always completely darkened by the fungus as are some run-off areas on the trunks. Other species of tree, e.g. ash or sycamore, had branchlets with considerably paler surfaces. It was noted that wetting by heavy rain produced a general and substantial darkening of nearly all surfaces with oak branchlets becoming black. It must be emphasized that any generalizations tend to obscure the often extreme variability which occurs between trees, particularly those of different species, in areas such as Cardiff with moderate levels of air pollution intermediate between very large industrial centres and rural regions.

\section{Behaviour of females before mating}

In 1986 the behaviour of 12 female moths released on to trunks immediately after eclosion was observed more closely. Eclosion usually occurs shortly before dusk. Newly emerged moths expanded their wings for about $30 \mathrm{~min}$ and then rested with wings outspread for a further hour or so (cf. Mikkola, 1984). The moths did not move until after dark when partial illumination was necessary to confirm their behaviour. Some then moved up to $2 \mathrm{~m}$ higher. They subsequently exhibited a period of about 10 min of wing vibration typical of body-heating behaviour. Nine moths then took flight; the other three could not be followed closely. Moths held for progressively more nights before release showed a decline in the tendencies to fly and to climb.

Female moths which had been held for three nights when released on to bark moved only short distances before 'clamping' their wings flat on to the surface. Shortly after dusk they moved, nearly always upwards or along horizontal branches to a position where they began releasing pheromone in a characteristic attitude of semi-closed, backward-held wings and abdomen bent outwards with the ovipositor protruded. All located females were 'calling' $30 \mathrm{~min}$ after dark but none had paired. Most movements from the release point were of less than $1 \mathrm{~m}$ but a few moths moved much higher up the tree, especially in Cardiff (see below). Some individuals released on trunks showed a positive movement on to any side branches encountered during climbing. Similarly some moths on branchlets (less than about $10 \mathrm{~cm}$ circumference) moved on to even smaller diameter side twigs. No moths were observed moving on to foliage. Movement on branches usually occurred along the lower surface. Pairing usually followed shortly after the first 30 min of darkness. At both sites less than $10 \%$ of pairings occurred after 23.00 hours.

\section{Behaviour of moths in copula}

The proportion of released females observed in copula was nearly $50 \%$ in each year in Somerset, but lower, about $33 \%$, in Cardiff. The lower value was associated with a higher disappearance of moths prior to observation, probably because of greater disturbance of them during transportation to the site. Several moths were actually observed climbing out of vision, and sometimes flying, immediately after release. In Somerset, six and three of the total of 93 pairing females mated two and three times, respectively, over consecutive nights. One of 23 pairing females at Cardiff mated twice, and another, three times. One of the multiple-mating females was observed laying eggs before pairing a second time. Two of the moths pairing three times were then boxed. They laid no eggs, although subsequent dissection showed many eggs were present. Moths in copula at night were usually inactive with wings held above the thorax. 

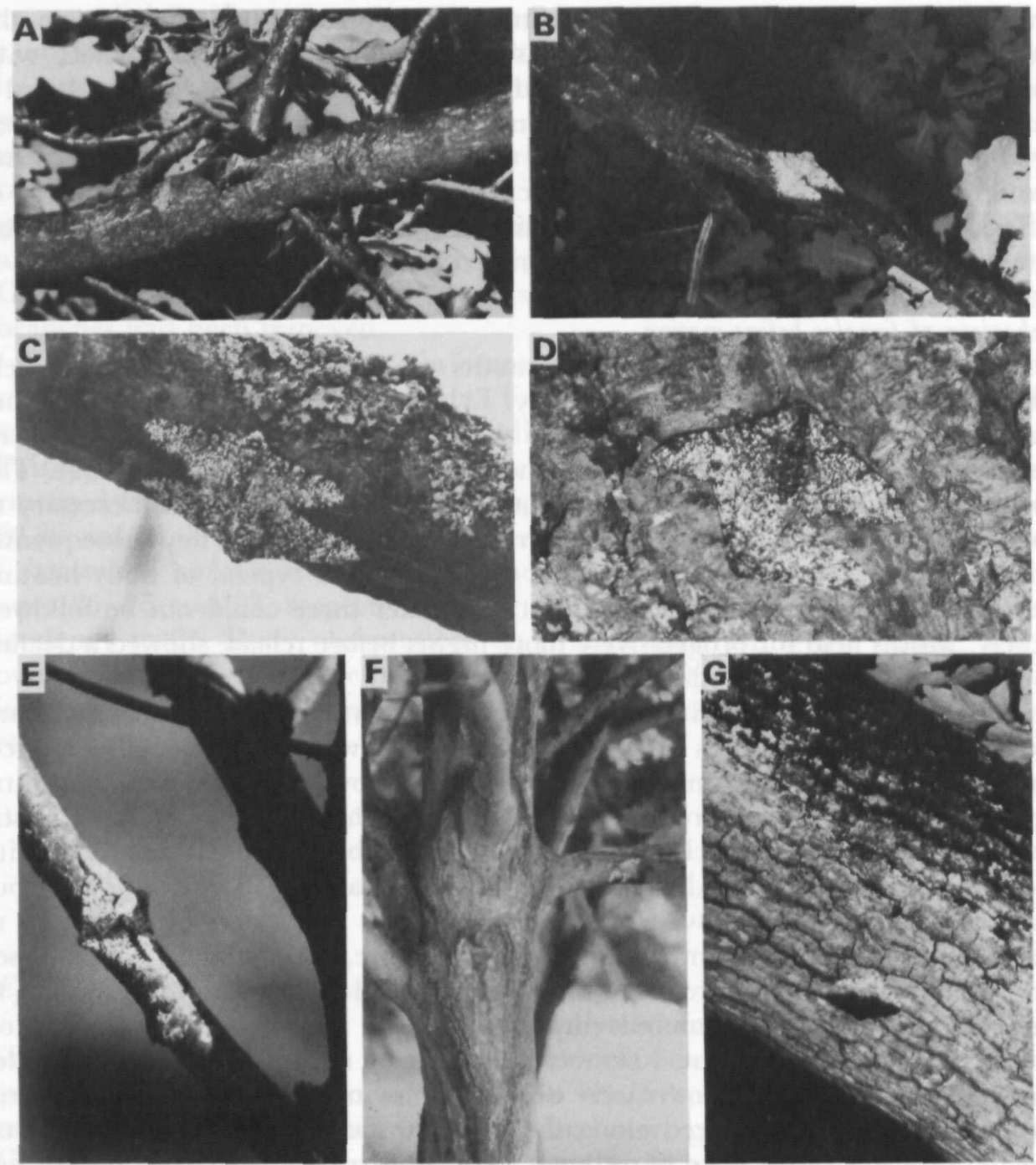

Figure 3. Photographs of pairing Biston betularia at rest on branches of varying circumference in Somerset [S] and Cardiff [CA]. A \& B, Below oak branchlets blackened with Torula herbarum [CA], camera angles were close to the vertical; C, side \& below on branch [S]; D, on side of a large oak branch close to the fork [CA], darker moth is an intermediate insularia; E, side \& above on branchlet [S]; F, on a horizontal side branch of a sycamore [CA] following release of female on the trunk at the foot of photo; G, at edge of crustose lichens on a main branch of an oak [CA], a typica moth is above the carbonaria.

By early morning the pairings had moved to take up daytime resting positions with wings fully spread and flattened on the bark. Movements from the position of pairing were nearly always less than $1 \mathrm{~m}$, and were often less than $25 \mathrm{~cm}$. Some characteristic resting positions are shown in Figs 3 and 4.

On main branches close to the horizontal, the bodies of over $80 \%$ of moths in copula were held nearly at right angles to the longitudinal axis (cf. Mikkola, 1984, for single males). Table 1 gives some details of the approximate position of pairings on branches. The general features of the positioning of pairings were 

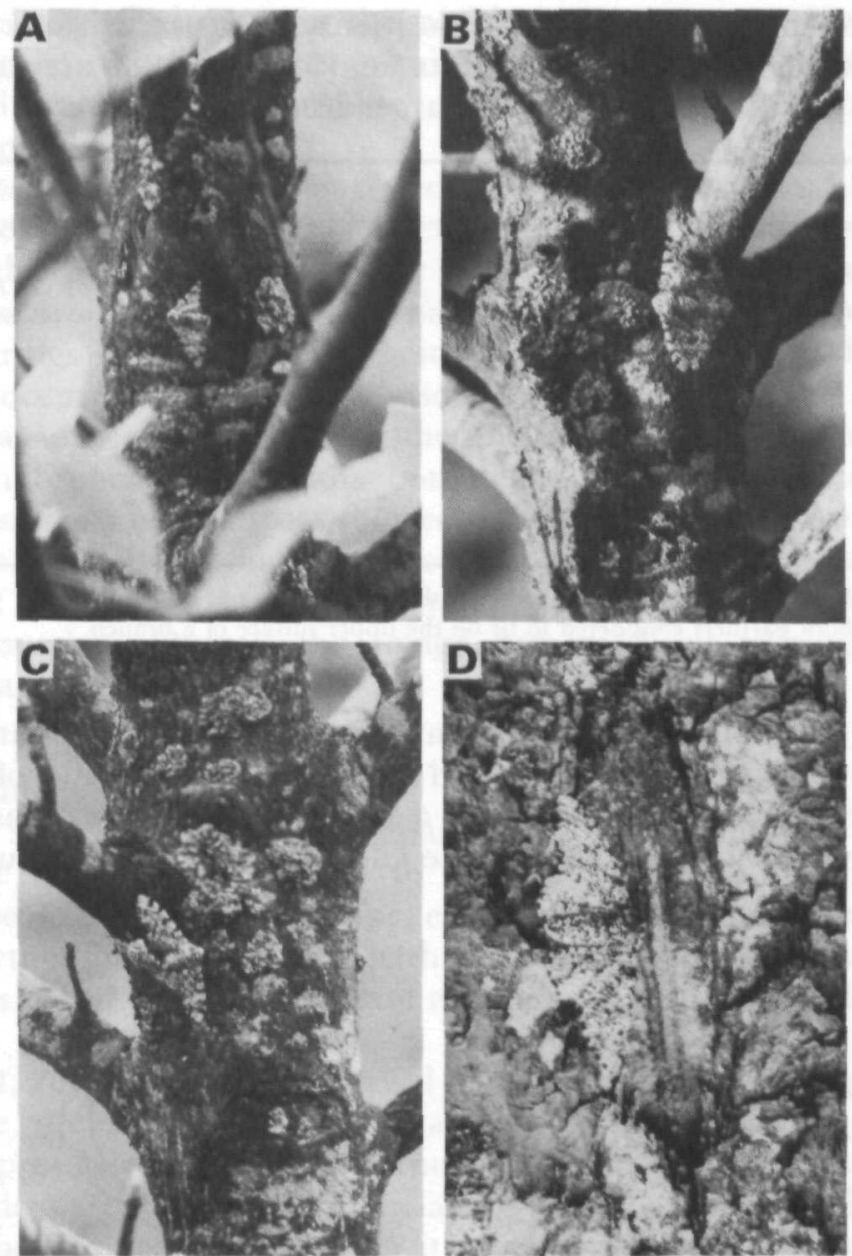

Figure 4. Photographs of pairing (A-C) or single (D) Biston betularia at rest on trunks with lichen floras in Somerset. In $\mathrm{C}$ one moth is attempting to rest below a side branch. The single female in D is resting along an old scar.

similar in Somerset and Cardiff. Figure 5 shows the approximate size of a pairing and illustrates typical positions on cross-sections of branches from Somerset. In 1985 and 1986 there was a strong bias towards resting on the lower half of branches (Table 1, $\chi^{2}$-tests: $P<0.05 ; P$ was n.s. in 1984). Examples of pairings resting on branches are shown in Fig. 3. Many pairings in Somerset were in the area immediately below the foliose lichens of the upper surfaces often with one partner against the lichens. Sometimes, particularly on branches of intermediate size, one partner (male or female) would rest on the foliose lichens and the other below. Two pairings in Cardiff were positioned about twothirds of the way up the side of main branches on oaks in the region of the boundary between the darkened moss of the upper surface and the middle zone of greyish crustose lichens. A further three were at the boundary of the crustose lichens and the lower bare surface. The position of pairings relative to the longitudinal axis means that they can rest readily underneath branches with a 
Table 1. The approximate resting positions of Biston betularia in copula on branches (notation as in Fig. 5); the data for 1984 and 1986 are subdivided into smaller and larger branches

\begin{tabular}{|c|c|c|c|c|c|c|c|}
\hline \multirow[b]{2}{*}{ Site } & \multirow[b]{2}{*}{ Year } & \multirow[b]{2}{*}{$\begin{array}{c}\text { Branch } \\
\text { size }\end{array}$} & \multicolumn{4}{|c|}{ Position on branch } & \multirow[b]{2}{*}{ Total } \\
\hline & & & Below & $\begin{array}{l}\text { Side \& } \\
\text { below* }\end{array}$ & $\begin{array}{l}\text { Side \& } \\
\text { above } †\end{array}$ & Above & \\
\hline Somerset & 1984 & $\begin{array}{l}\text { Small } \\
\text { Large }\end{array}$ & $\begin{array}{l}6 \\
1\end{array}$ & $\begin{array}{l}6 \\
0\end{array}$ & $\begin{array}{l}4 \\
5\end{array}$ & $\begin{array}{l}3 \\
0\end{array}$ & $\begin{array}{r}19 \\
6\end{array}$ \\
\hline Somerset & 1985 & All & 13 & 2 & 5 & 2 & 22 \\
\hline Cardiff & 1986 & $\begin{array}{l}\text { Small } \\
\text { Large }\end{array}$ & $\begin{array}{l}3 \\
2\end{array}$ & $\begin{array}{l}2 \\
6\end{array}$ & $\begin{array}{l}1 \\
3\end{array}$ & $\begin{array}{l}0 \\
0\end{array}$ & $\begin{array}{r}6 \\
11\end{array}$ \\
\hline
\end{tabular}

* In calculations both partners considered to be on the lower surface of a branch;

$\uparrow$ In calculations both partners considered to be on the upper surface of a branch.

circumference as small as $8 \mathrm{~cm}$. On branchlets of a smaller circumference, one partner usually rested underneath and the other on the side of the branch. Sometimes one partner rested partly up a side branchlet. The occasional pairing occurring on twigs showed a remarkable folding of the moths around the whole
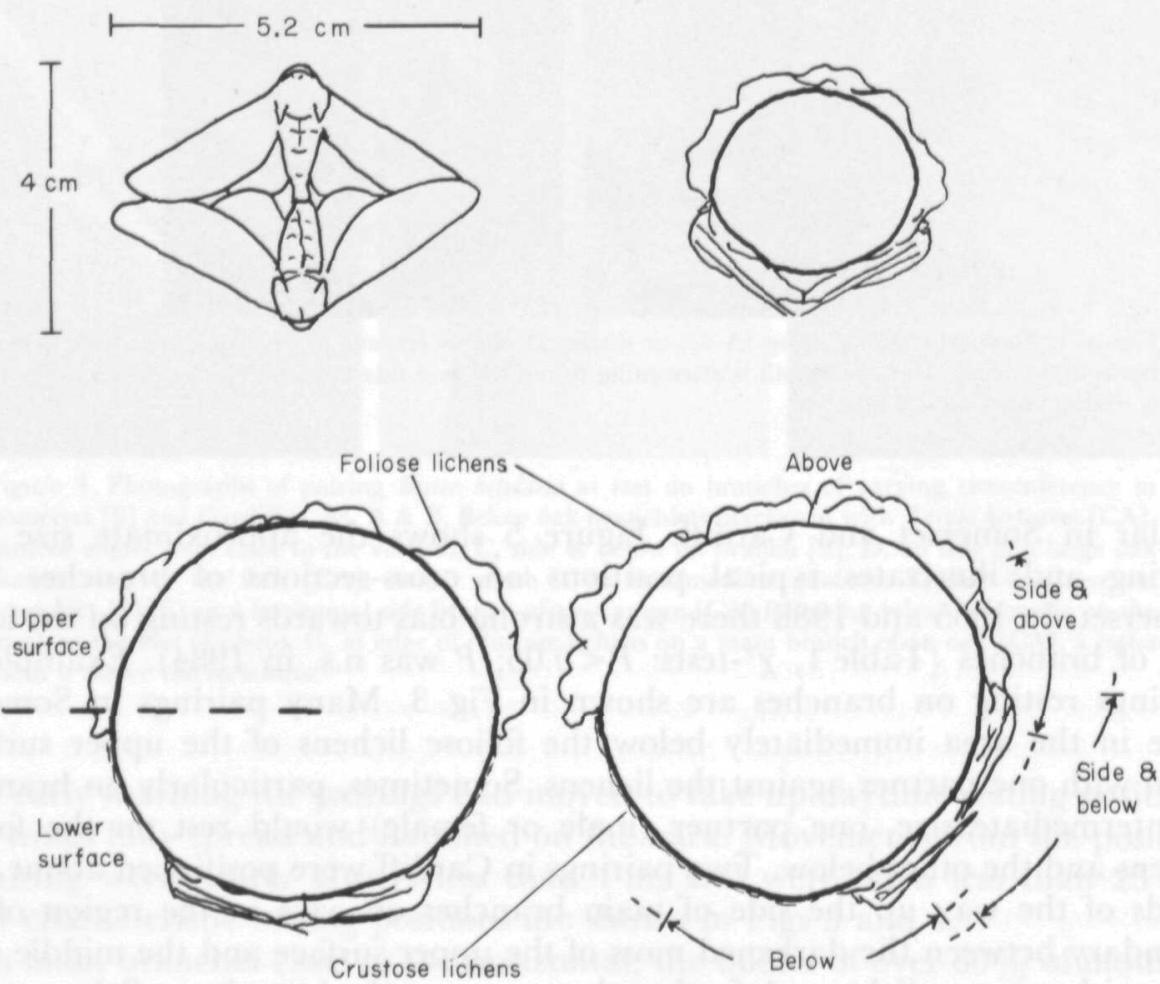

Figure 5. Approximate dimensions of a pairing of Biston betularia, with cross-sections of branches of 9 and $18 \mathrm{~cm}$ in circumference from Somerset showing lichens and pairings in characteristic positions. The notation used in describing positions on branches is given. 
surface. Five recorded changes in the position of pairings on branches during daylight appeared to be responses to rain, wind or strong sunshine. Two pairs moved around branches from sunshine to shade. Movement occurs in a series of short rhythmic jerks.

Moths in copula on trunks usually rested with their bodies at right angles to the vertical axis (examples in Fig. 4). For example, 20 of 38 pairings on trunks in 1984 were in this position, and a further nine close to it. This resting orientation was almost invariably taken up on narrower trunks, as it was on vertical branches. Pairings on trunks often rested against or amongst foliose lichens where these occurred. They were also frequently associated, especially in Cardiff, with a surface feature such as the side of a bump, crevice or hollow (see Fig. 4). As in branch-resting pairs both females and males occurred in the uppermost position. Four pairings showed daytime movements from sunshine to shade. Almost all pairings on trunks overlapped at least one pair of wings. About $75 \%$ of all pairings showed some merging of one pair of wings, frequently with actual overlap. Overall the image presented by pairings was rather variable in shape and size (see Figs 3 \& 4).

\section{Separation of pairings and oviposition}

More than $90 \%$ of pairings had separated by 22.30 hours on the day after mating. Some inspections at 14.30 to 15.30 hours detected only occasional separations before late afternoon or early evening. Four pairings actually remained together for a second day, perhaps in response to particularly cold and wet conditions. Moths usually separate and move apart a short distance, up to about $20 \mathrm{~cm}$.

In Somerset, 26 females were observed laying eggs during the inspections after dark. Of these, the majority (17) were laying in recesses amongst foliose lichens by inserting protruded ovipositors. Another ten females were laying eggs in cracks or crevices. Some of the females laying on a thallus (or thalli) of a foliose lichen continued to use it, resting on it or next to it during the day. Others moved to a new thallus. Females in Cardiff had no available foliose lichen thalli and the five observed ovipositing were using cracks (see an example in Fig. 6). Some of them searched widely over the bark for cracks, moving both up and down the trunk or branch with wings held nearly closed above the body and ovipositor protruded. A more active searching behaviour may be typical of polluted environments because of the absence of foliose lichens. Our observations indicate that alternative laying sites are scarce on narrower branches which will necessitate movement to larger branches. Females in all conditions are unlikely to fly once egg-laying has begun.

\section{Crypsis and survivorship of released moths}

The observations described above indicate the strong tendency to climb of newly emerged moths and confirm Mikkola's (1984) conclusion that the moth is adapted for resting on small, horizontal branches. They show that moths resting on main branches or branchlets in Somerset frequently tended to be aligned across or very close to the midline between regions dominated by foliose (with fruticose) and crustose lichens, respectively. Similarly, in Cardiff, moths on main branches were often associated with the boundaries between zones of differing 
background. This behaviour could have a profound effect on the degree of matching between insect and background, especially for moths in copula when each individual was in some cases resting at least partly on different backgrounds (see Figs 1, 3 \& 4). Although most melanic individuals in Somerset appeared to be less cryptic on their resting background than non-melanics, there were exceptions. The latter often included members of pairings where the melanic was the lower moth associated with a midline on a branch. On the uniformly dark or black branchlets in Cardiff, typica moths or pairings involving typica were clearly highly contrasted with their background in comparison to melanics (see Fig. 3). In contrast, for pairings involving typica or insularia, on main branches or trunks these phenotypes often, but not always, appeared substantially more cryptic than carbonaria (see Discussion).

There was little evidence of predation of moths on the release trees during the night. One set of wings was found at the base of a tree soon after the dawn following release. The great majority of moths not recorded after release had probably climbed too high or taken flight. In contrast, there was evidence of daytime predation by insectivorous birds which were abundant and diverse at each site. In Somerset, coal tits Parus ater were observed foraging amongst foliose lichens, frequently removing them in strips. Both titmice (Parus spp.) and tree creepers (Certhia familiaris) were active at the Cardiff site. On three occasions at each study site the remains of moths in copula were found on the ground below trees.

Table 2. Life-table data for the indicated cohorts of released female Biston betularia from the time (evening) of pairing (any second and third matings are excluded from analysis). Manly's (1973) method is used to compare the survivorship curves as indicated. The daily selective value $( \pm \mathrm{SE})$ of the second cohort relative to the first $(=1.0)$ is given together with the $t$ value

\begin{tabular}{|c|c|c|c|}
\hline \multirow[b]{2}{*}{ Day } & \multicolumn{3}{|c|}{ Numbers surviving } \\
\hline & typica & insularia & carbonaria \\
\hline \multicolumn{4}{|c|}{ (a) Somerset, 1984} \\
\hline 0 & 9 & 8 & 6 \\
\hline 1 & 7 & 4 & 2 \\
\hline 2 & 5 & 2 & 1 \\
\hline 3 & 4 & 1 & 0 \\
\hline 4 & 4 & 1 & 0 \\
\hline 5 & 3 & 1 & 0 \\
\hline 6 & 0 & 0 & 0 \\
\hline \multicolumn{4}{|c|}{$\begin{array}{l}\text { carbonaria } \times \text { typica: } 2.419 \pm 0.819, t=1.73,0.1>P>0.05 \\
\text { carbonaria } \times \text { insularia }+ \text { typica: } 2.125 \pm 0.730, t=1.54, P \text { is n.s. }\end{array}$} \\
\hline \multicolumn{4}{|c|}{ (b) Cardiff, 1986} \\
\hline 0 & 11 & - & 12 \\
\hline 1 & 7 & - & 2 \\
\hline 2 & 1 & - & 1 \\
\hline 3 & 0 & - & 0 \\
\hline
\end{tabular}


Table 3. The survivorship of released female Biston betularia in different pairing combinations over the first $24 \mathrm{~h}$ after mating. A distinction is made between assortatively and disassortatively mating moths and selected statistical comparisons of survival rate using Fisher's Exact Test are given.

\begin{tabular}{|c|c|c|}
\hline \multirow[b]{2}{*}{ Pairing } & \multicolumn{2}{|c|}{ Survival } \\
\hline & Yes & No \\
\hline \multicolumn{3}{|l|}{ (a) Somerset, 1984} \\
\hline typica $\times$ typica & 6 & 1 \\
\hline insularia $\times$ insularia & 1 & 1 \\
\hline carbonaria $\times$ carbonaria & 1 & 1 \\
\hline $\begin{array}{l}\text { All unlike } \\
\text { typica } \times \text { typica } v \text {, all others: } 0.1>P>0.05 \text {. }\end{array}$ & 5 & 7 \\
\hline \multicolumn{3}{|l|}{ (b) Cardiff, 1986: } \\
\hline Melanic $\times$ melanic* & 0 & \\
\hline Non-melanic $\times$ non-melanic ${ }^{\dagger}$ & 6 & 4 \\
\hline typica $\times$ carbonaria & 4 & 5 \\
\hline \multicolumn{3}{|l|}{ Melanic $\times$ melanic $v$. all others: $P<0.05$} \\
\hline
\end{tabular}

Approximately equal numbers of the three phenotypes of $B$. betularia were released in Somerset from 4 to 28 May 1984 and of carbonaria and typica at Cardiff from 7 June to 8 July 1986. These periods were within the flight period of the local populations (other moths in 1984 were released earlier and before leaf growth). Inspection of the life-table data for these small cohorts from the night of pairing (Table 2) indicates that the mortality rate of carbonaria in comparison to the other phenotypes is high. However, application of Manly's (1973) method shows that these differences are not significant (Table 2). Overall mortality was higher at Cardiff $(2.178 \pm 0.465, t=2.53, P<0.05)$. When the individual phenotypes are considered only typica exhibits a significantly higher mortality at Cardiff $(2.477 \pm 0.486, t=3.04, P<0.01)$.

Table 3 presents the survivorship data combined for pairings between like or unlike moths at each site. More data of this form are required to test adequately Kettlewell's hypothesis of differential survival of assortatively and disassortatively mating moths. Our limited data suggest that at Cardiff, carbonaria $\times$ carbonaria pairings have a relatively high mortality while in Somerset, typica $\times$ typica pairings may have a relatively low mortality.

\section{Cage experiments}

\section{Influence of lichens on movement of moths}

Table 4 summarizes the numbers of female moths resting on the ends of each of the three different branches $24 \mathrm{~h}$ after release. Branch 1 with luxuriant foliose 
Table 4. Numbers of female Biston betularia released and resting $24 \mathrm{~h}$ later on the ends of each branch in the cage experiments.

\begin{tabular}{lccccc}
\hline & & & \multicolumn{2}{c}{ Present after $24 \mathrm{~h}$} \\
\cline { 5 - 6 } Branch & End & $\begin{array}{c}\text { Presence of } \\
\text { lichens* }\end{array}$ & $\begin{array}{c}\text { Releases } \\
(\mathcal{N})\end{array}$ & $\begin{array}{c}\text { On end of } \\
\text { release }(\mathcal{N})\end{array}$ & $\begin{array}{c}\text { From other } \\
\text { ends }(\mathcal{N})\end{array}$ \\
\hline 1 & A & + & 11 & 3 & 11 \\
& B & + & 13 & 6 & 6 \\
2 & A & - & 11 & 0 & 1 \\
3 & B & + & 13 & 9 & 15 \\
\hline
\end{tabular}

*+, Present; -, absent.

lichens on each end and branch 3 with no lichens on either end each show no difference between their two ends in the rate of movement of moths away to other areas of the cage $\left(\chi^{2}=0.42\right.$ and 1.58 , respectively). In contrast, branch 2 with foliose lichens on only one end shows a lower rate of emigration from this end $\left(\chi^{2}=6.19, P<0.05\right)$. Similarly, the end of this branch with lichen cover attracted more resting moths than the other end devoid of lichens $\left(\chi^{2}=7.57\right.$, $P<0.01)$. Overall, while similar numbers of moths were released on lichen-free and lichen-present branch ends, many more moths were resting $24 \mathrm{~h}$ later on those regions with lichens than without $\left(\chi^{2}=9.45, P<0.01\right)$.

The daytime resting behaviour was examined in more detail during early morning inspections. On areas of the branches where foliose lichens occurred, 12 moths rested amongst these on the upper surface of the branches and 17 rested on the lower sides immediately below and adjacent to the foliose lichens where crustose lichens grew (see Fig. 6). The side-resting moths rested with their bodies in a vertical position position either head-up or head-down. The other 12 moths rested below the branches. The results indicate a similar preference for resting on lower surfaces as found for pairing moths in the field.

At 08.00 hours a lower proportion of typica than of insularia and carbonaria combined were resting underneath branches (Table 5; $\chi^{2}=5.11, P .<0.05$ ). There was no difference between the phenotypes in the proportion on branch regions with foliose lichens $\left(\chi^{2}=2.06\right.$, d.f. $\left.=2\right)$.

Table 5. Comparison of the daytime resting positions of female Biston betularia of different phenotypes in the cage experiments

\begin{tabular}{|c|c|c|c|c|c|c|c|}
\hline \multirow[b]{2}{*}{ Phenotype } & \multirow[b]{2}{*}{$\begin{array}{l}\text { Releases } \\
(\mathcal{N})\end{array}$} & \multicolumn{6}{|c|}{ Resting position } \\
\hline & & Below & $\begin{array}{c}\text { Side \& } \\
\text { below }\end{array}$ & $\begin{array}{l}\text { Side \& } \\
\text { above }\end{array}$ & $\begin{array}{c}\text { Off } \\
\text { branches }\end{array}$ & $\begin{array}{c}\text { With } \\
\text { lichens }\end{array}$ & $\begin{array}{l}\text { Without } \\
\text { lichens }\end{array}$ \\
\hline Iypica & 23 & 2 & 6 & 7 & $8^{*}$ & 14 & 2 \\
\hline insularia & 25 & 10 & 8 & 4 & $3 *$ & 16 & 7 \\
\hline carbonaria & 25 & 9 & 6 & 4 & 6 & 13 & 6 \\
\hline
\end{tabular}

*Includes one moth on the end surface of a branch. 

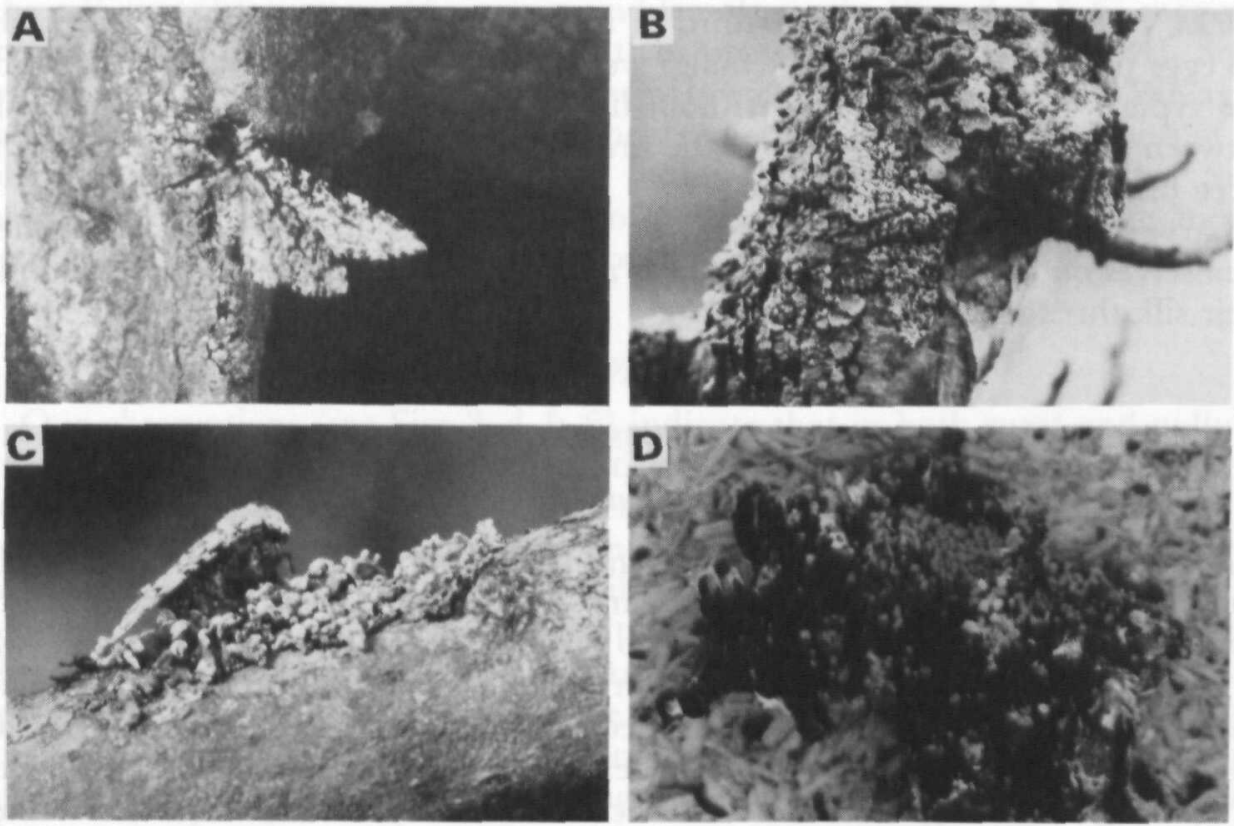

Figure 6. Photographs of ovipositing Biston betularia with eggs. A, Laying eggs in a crack at night on a sycamore in Cardiff; B, daytime resting position next to a foliose lichen thallus below which the female laid eggs over a 4 day period in Somerset; C, laying eggs in daylight below a foliose lichen thallus in Somerset; D, ventral surface of a thallus showing eggs.

\section{Daytime movement of moths}

Most moths remain inactive during daylight hours. However, seven females moved below branches and six, down on to the sides between 07.00 and 20.30 hours (total $\mathcal{N}=67$ ). These moves were probably in response to sunshine; some individuals were observed to move following exposure to sunshine. Of the 15 moths which were off the branches at 08.00 hours, nine moved on to branches during the day.

\section{Oviposition}

Searching for egg-laying sites involved slow movement and continuous probing of the branch surface with the ovipositor extended. A potential site would be investigated by additional probing before laying commenced. Individuals appeared to move to another area of the branch if no suitable site was encountered within a short time. Once oviposition began at a site, females often rested on or next to it during the day (see Fig. 6).

Thirteen females were seen 'calling' during the experiment and may not have laid any eggs. Thirty-five females were observed ovipositing after dark $(22.30$ hours) on the evening of release, 26 amongst foliose lichens and nine in cracks. Seven of the females using cracks were in regions without lichens. Nine females were also seen laying eggs between 08.00 and 18.00 hours the next day and a further 29 up to 20.30 hours. Twenty-nine of the females laying during the day used lichens. Eggs were usually laid beneath lichen thalli (Fig. 6).

At the end of the experiment, counts were made of the eggs on the branches. Totals of 6644 and 2290 eggs were found associated with foliose lichens and 
cracks, respectively (about one-third of the eggs would have already hatched). No eggs (and only one resting female) were found on the end of branch 2 which was typical of living branches without lichens. There was no clear relationship between the number of eggs and the areas covered by different lichens on the three branch ends with lichens.

Larvae on hatching from eggs on the branches immediately suspended themselves on silk (Fig. 6). If there was an air current they were dispersed with their silk threads.

\section{DISCUSSION \\ Experimental design}

A critical feature of our field experiments is the holding of the virgin females for three nights before release. It is necessary to examine whether this causes such manifold effects on their behaviour as to give results which are unrepresentative of what actually occurs in nature. There are two principal arguments against this possibility. Firstly, females allowed to mate on the first evening after eclosion and then released in our cage experiments showed very little tendency to fly and were in general no more active than the field releases were after mating. Secondly, females held in sleeves exhibit a short period of flight activity on the evening after emergence but little or none on subsequent nights. Initially they also show a strong tendency to climb. Therefore, the only substantial effects of our holding procedure on the behaviour of females are apparently to overcome an initial dispersal flight and probably to reduce climbing after settling. This tendency for females to fly only before mating on the first night is consistent with Kettlewell's (1973) comment that a high proportion of females collected at light traps are virgin.

Our experiments do not quantify the frequency distribution of resting sites within trees used by moths in the wild. The results are biassed by the sites within trees where moths were released. We are able to describe the resting behaviour of moths in different parts of trees and to comment on the likelihood of preferences shown by moths in the wild and of effects of behaviour on predation. Future work will need to quantify the sites used in the wild, for example by attempting to study the settling of females after their initial dispersal flights.

\section{Moth resting behaviour}

Mikkola (1984) suggested from observations of single males in a cage that the normal resting position of $B$. betularia is "beneath small, more or less horizontal branches, probably high up in the canopies". Our results show that the species also rests on more vertical surfaces and on the side of branches of varying size, although under-branch resting still predominates, especially on branchlets. Many branches in the canopy rise at angles closer to the vertical than the horizontal. The discovery of larvae at considerable distances from any large trees (Liebert, unpubl. data) and their behaviour on hatching from eggs massed under lichen thalli support the occurrence of passive wind dispersal of larvae (see Kettlewell, 1973). The outer canopy is the ideal site for such dispersal. 
Overall, our observations of pairings and female moths (Figs 3, 4 \& 6) suggest a more varied choice of resting position than proposed by Mikkola (1984). Some will rest on main branches or trunks (see Howlett \& Majerus, 1987). We agree with Mikkola's critique of field experiments to estimate the relative fitness of the phenotypes of $B$. betularia by using moths exposed on tree trunks. Such predation experiments must take into account the full range of the moth's resting sites in more, or less exposed positions.

\section{Consequences for crypsis of the phenotypes}

Our observations (see Figs 3, 4 \& 6) indicate that in both rural and polluted environments the precise resting position of moths, especially of pairings, in relation to the quite clear-cut patterns of epiphytic and colour zones on branches will have profound effects on the degree of background matching or crypsis and therefore on the probability of detection by a visually hunting predator. In the absence of air pollution, the nature of epiphytic floras and therefore, of colour and texture of bark, is dependent on such factors as the species of tree, age and acidity of the bark, light intensity and effects of the growth form of trees on drainage of rainwater and nutrients. Varying conditions of light intensity (time of day), shading and wetness of bark will also influence the crypsis of resting moths.

In clean, rural environments the generally pale but variegated coloration of the tree surfaces provides the typica form with a cryptic resting background. Moths resting in the canopies will inevitably come into close proximity with foliose lichens. Females show a strong preference to oviposit under a thallus/thalli of these lichens. We agree that the typica phenotype, either when unpaired (Tutt, 1896) or when paired assortatively (Mikkola, 1984), is likely to benefit from its resemblance to (foliose) lichen thalli. This effect is probably enhanced for single, egg-laying females, by their behaviour of remaining very close to a thallus during the day, and for pairings, by their positioning on branchlets and their tendency to overlap part of their wing surfaces (Figs 3, 4 \& 6 ). The last behaviour increases the irregularity of the shape of pairings which may also decrease the likelihood of predators forming a search image. This 'mimicry' of foliose lichens may account for the specialized behaviour of the species to remain in copula for nearly $24 \mathrm{~h}$ (Mikkola, 1984).

Tutt (1896) graphically describes the intense blackness of the industrial environment in Britain in the late 19th century which favoured the spread of an entirely 'negro' form of B. betularia by natural selection. Kettlewell (1973) notes in general terms the way in which particulate air pollution, especially soot, builds up on trees depending on the drainage pattern. In parallel with this darkening, the gaseous components of air pollution, especially sulphur dioxide, killed the lichens which had previously given the trees a pale colour and, particularly in the case of foliose species, had favoured typica. Completely blackened resting backgrounds can only favour carbonaria (Fig. 7).

However, the polymorphism is not a simple black-and-white 'picture'. Kettlewell (1973) describes how the effects of both components of air pollution declines away from their source. Species of lichens vary in their susceptibility to sulphur dioxide (see e.g. Hawksworth \& Rose, 1970; Seaward \& Hitch, 1982). Several crustose lichens can tolerate higher levels of surface acidity than the 


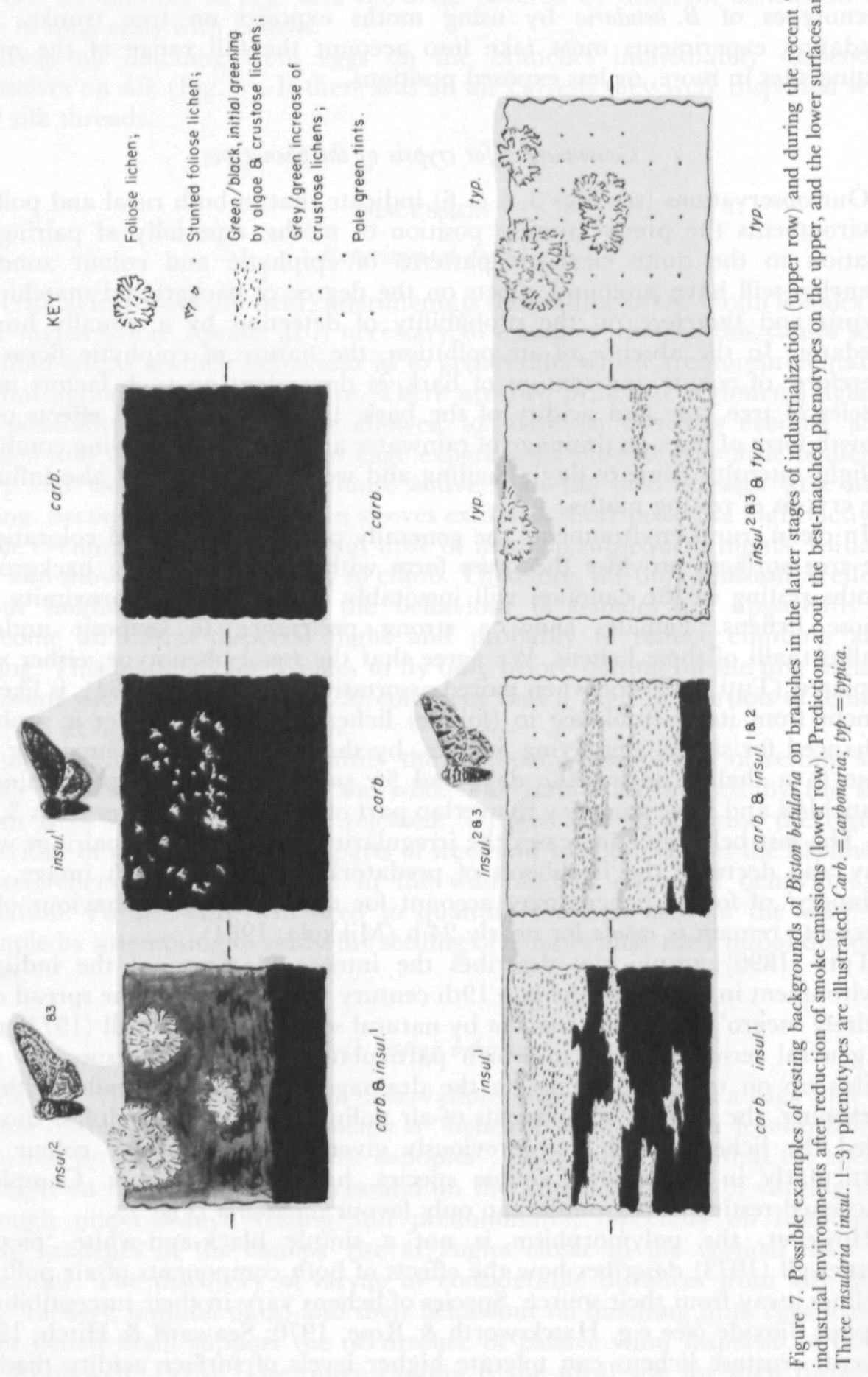


most tolerant foliose species. Intermediate stages of pollution with varying degrees of blackening, some establishment of algae and crustose lichens, and where foliose lichens are scarce, stunted or absent will produce environmental variability and may lead to the presence of the intermediate insularia complex. Some examples of resting backgrounds likely to favour insularia are shown in Fig. 7. The darker body coloration of this complex than of typica probably has a major influence on its crypsis. However, the likelihood of substantial frequencies of insularia probably also depends on initial frequencies and the rate of gene flow from surrounding regions. Narrower belts of land influenced by changes in air pollution may exhibit comparatively unchanged phenotype frequencies (which appear 'mismatched') because of high rates of gene flow associated with migration from surrounding regions (an example is the Cynon valley in South Wales, Lees, 1981). We believe that in addition to adult movement (e.g. Bishop, 1972 ), it is critical to quantify the frequency distribution of wind dispersal by hatching larvae (e.g. using wind-tunnel experiments) as this is likely to involve substantial long-distance movement.

The only evidence we obtained of any difference in behaviour between the phenotypes was a weaker tendency of typica females to rest underneath the branches in the cage experiments. Mikkola (1984) found that a lower proportion of typica, than carbonaria males rested on the branches in his experimental cage. Any differences in resting site selection could clearly substantially influence patterns of visual selection (see e.g. Steward, 1985; Howlett \& Majerus, 1987).

\section{On pollution effects underlying temporal changes in the polymorphism}

The establishment of smokeless zones in Britain after the clean air legislation in 1956 led to falls in smoke and sulphur dioxide pollution in industrial regions. The decline in smoke was rapid but that in sulphur dioxide was more gradual (see Lees, 1981). Declines in the frequency of carbonaria are correlated with the reductions in air pollution (Clarke et al., 1985; Cook et al., 1986). The long term monitoring by the Clarke et al. study of $B$. betularia at West Kirby on the Wirral in northwest England, provides the best documented example. The initial reduction in particulate air pollution and a lightening of tree surfaces clearly played a part in the decline in carbonaria at West Kirby. Nevertheless, the best fit to the observed change in frequency is given when the fitness of typica is linearly correlated with the level of sulphur dioxide. However, Clarke et al. consider that foliose lichens remain virtually absent at West Kirby due to the dominance of aggressive, opportunistic epiphytes, and that there may be a strong non-visual component to the selection in favour of typica. One of us (T.G.L.) noted the colour of bark and lichens present on the Wirral in 1967, 1971-2 and 1976. In the last year, although most of the bark surfaces were green, grey foliose lichens were seen at low levels on the branches and trunks of some trees near West Kirby. Seaward \& Hitch (1982), in their atlas of lichens, show that the grey foliose lichen $H$. physodes is present; they also indicate that its upper winter limit of sulphur dioxide tolerance is $100 \mu \mathrm{g} \mathrm{m}^{-3}$ and that it responds rapidly to fluctuating levels of pollutant. Clarke et al. (1985) show that this level of sulphur dioxide was reached in about 1970 and that it was halved again by 1975. It is noteworthy that carbonaria only began to show any marked decline in the early 


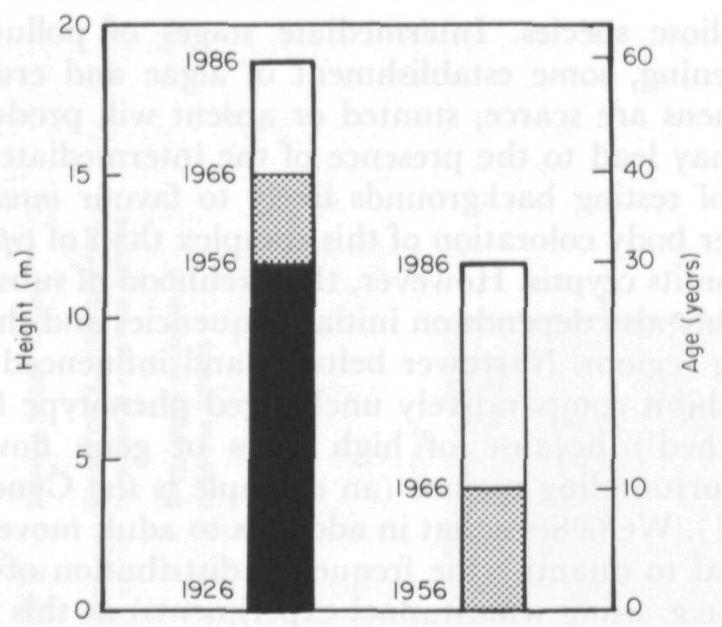

Figure 8. Diagram representing the growth of oak trees aged 30 and 60 years in an industrial environment with a history of intermediate levels of air pollution. Solid shading indicates blackened bark prior to clean air legislation in 1956 and stippling, bark in the next 10 years during which smoke emissions were more than halved in Britain. (Data on growth rate by courtesy of the Forestry Commission.)

1970 s, increasing rapidly in the later 1970s. This period thus coincided with reductions of sulphur dioxide to levels below which some grey foliose lichens could be expected to appear, probably especially on the upper surfaces of canopy branchlets and largely out of sight to observers on the ground. It would be interesting to know more about factors regulating the re-establishment of foliose lichens on different parts of the tree; for example, do higher levels of residual particulate pollutants on the trunk slow this process or promote the aggressive species of epiphytes?

In areas such as the Wirral, we must also consider that many smaller trees and many branches in the outer canopy of older trees have never experienced high particulate air pollution. This is illustrated in Fig. 8 for oak which is one of the slowest growing trees. The new growth of the canopy is unlikely to have become dominated by aggressive epiphytes or experienced other factors inhibiting establishment of foliose lichens. We believe that we need to know much more about the interactions between pollution, epiphytes and resting backgrounds of $B$. betularia, especially in the canopy, before we can be confident about our understanding of the evolution of industrial melanism in this species.

The change in the relative fitness of carbonaria and typica during 'recovery' of the environment may not be a steady one. In particular, because of the strong preference exhibited by females of both phenotypes to lay their eggs amongst foliose lichens and their tendency to rest on or adjacent to them during the day, even a low density of such lichens is likely to result in a pronounced selective disadvantage to carbonaria because of poor crypsis. In contrast, any resemblance of typica to a thallus of a foliose lichen will enhance its crypsis. Therefore, early in the re-establishment of such lichens, carbonaria may be predicted to lose any residual selective advantage it experienced due to the heterogeneity in resting backgrounds characteristic of environments with moderate loads of air pollution. The presence of foliose lichens in the tree canopies at West Kirby may 
account for the rapid increase in typica, rather than in insularia, observed by Clarke et al. (1985).

Our data on the survivorship of pairings and of egg-laying females are rather limited and must be treated with caution although they do suggest the existence of differential predation. The discovery of some bird-pecked remains of pairings demonstrates that predation by birds occurs at low densities of $B$. betularia comparable to those in natural populations (Bishop, 1972; Bishop, Cook \& Muggleton, 1978). We believe that a most important aspect of our experiments is that they now provide the basis of a method for measuring the relative crypsis (see Endler, 1984) and differential mortality of the different phenotypes as living females, either in copula or when egg-laying, at natural resting sites on different backgrounds. More data are now required based on a replicated experimental design in environments differing in pollution effects and using cohorts released in more standardized sites (e.g. branchlets or smaller branches) within particular species of trees to provide some rigorous estimates of visual selection.

\section{ACKNOWLEDGEMENTS}

We would like to thank Sir Cyril Clarke and Drs L. M. Cook, D. R. Lees and M. R. D. Seaward for their comments on a draft or the manuscript of this paper. Dr Seaward and Mrs P. N. Bartlett kindly assisted with the identification of epiphytes. Phillip Brakefield and Viv Williams helped with the production of the Plates.

\section{REFERENCES}

BISHOP, J. A., 1972. An experimental study of the cline of industrial melanism in Biston betularia (L.) (Lepidoptera) between urban Liverpool and rural North Wales. Journal of Animal Ecology, 41: 209-243.

BISHOP, J. A. \& COOK, L. M., 1975. Moths, melanism and clear air. Scientific American, 232: 90-99.

BISHOP, J. A., COOK, L. M. \& MUGGLETON, J., 1978. The response of two species of moths to industrialisation in northwest England. II. Relative fitness of morphs and population size. Philosophical Transactions of the Royal Society of London, Series B, 181: 517-540.

BISHOP, J. A., COOK, L. M., MUGGLETON, J. \& SEAWARD, M. R. D., 1975. Moths, lichens and air pollution along a transect from Manchester to North Wales. Journal of Applied Ecology, 12: 83-98.

BRAKEFIELD, P. M., 1987. Industrial melanism: do we have the answers? Trends in Ecology \&o Evolution, 2: $117-122$

CLARKE, C. A., MANI, G. S. \& WYNNE, G., 1985. Evolution in reverse: clean air and the peppered moth. Biological Journal of the Linnean Society, 26: 189-199.

COOK, L. M., MANI, G. S. \& VARLEY, M. E., 1986. Postindustrial melanism in the peppered moth. Science, 231: 611-613.

CREED, E. R., LEES, D. R. \& BULMER, M. G., 1980. Pre-adult viability differences of melanic Biston betularia (L.) (Lepidoptera). Biological Journal of the Linnean Society, 13: 251-262.

ENDLER, J. A., 1984. Progressive background matching in moths and a quantitative measure of crypsis. Biological Journal of the Linnean Society, 22: 187-231.

HAWKSWORTH, D. L. \& ROSE, F., 1970. Qualitative scale for estimating sulphur dioxide air pollution in England and Wales using epiphytic lichens. Nature, London, 227: 145-148.

HOWLETT, R. J. \& MAJERUS, M. E. N., 1987. The understanding of industrial melanism in the peppered moth (Biston betularia) (Lepidoptera: Geometridae). Biological Journal of the Linnean Society, 30: 31-44.

KETTLEWELL, B., 1973. The Evolution of Melanism. Oxford: Clarendon Press.

LEES, D. R., 1981. Industrial melanism: genetic adaptation of animals to air pollution. In J. A. Bishop \& L. M. Cook (Eds), Genetic Consequences of Man Made Change: 129-176. London: Academic Press.

MANI, G. S., 1980. A theoretical study of morph ratio clines with special reference to melanism in moths. Proceedings of the Royal Society of London B, 210: 299-316.

MANI, G. S., 1982. A theoretical analysis of the morph frequency variation in the peppered moth over England and Wales. Biological Journal of the Linnean Society, 17: 259-267.

MANLY, B. F. J., 1973. A note on the estimation of selective values from recaptures of marked animals when selection pressures remain constant over time. Researches on Population Ecology, 14: 151-158. 
MIKKOLA, K., 1979. Resting site selection of Oligia and Biston moths (Lepidoptera; Noctuidae and Geometridae). Annales Entomologici Fennici, 45: 81-87.

MIKKOLA, K., 1984. On the selective forces acting in the industrial melanism of Biston and Oligia moths (Lepidoptera: Geometridae and Noctuidae). Biological Journal of the Linnean Society, 21: 409-421.

SEAWARD, M. R. D. \& HITCH, C. J. B., 1982. Atlas of the Lichens of the British Isles, 1. Cambridge: Institute of Terrestrial Ecology.

STEWARD, R. C., I985. Evolution of resting behaviour in polymorphic 'industrial melanic' moth species. Biological Journal of the Linnean Society, 24: 285-293.

TUTT, J. W., 1896. British Moths. George Routledge \& Sons. 